\title{
CONTAINING HIV AND AIDS: CREATING A READERS' THEATRE SCRIPT FOR PROFESSIONAL LEARNING IN HIGHER EDUCATION
}

\author{
L. van Laren* \\ e-mail: vanlarenl@ukzn.ac.za
}

\section{K. Pithouse-Morgan*}

e-mail: pithousemorgan@ukzn.ac.za

\author{
L. Masinga* \\ e-mail: masingal@ukzn.ac.za
}

*School of Education

University of KwaZulu-Natal

Durban, South Africa

\section{ABSTRACT}

We worked together to create a readers' theatre script as a vehicle for learning about using everyday objects to open up conversations in a workshop on HIV and AIDS curriculum integration research in higher education. Through creating the script and a series of interconnected dialogue pieces we uncovered experiences and understandings of productive containment and connections in professional learning in higher education, especially in relation to sensitive areas such as HIV and AIDS. We demonstrate how we composed the readers' theatre script as a creative analytical practice to gain insights into our learning, while also discovering more about how this arts-based research practice can enhance individual and collaborative meaning making. Through arts-based collaborative self-study research we were able to deepen and extend our learning in a supportive and inventive manner, which fuelled hopefulness and a renewed sense of purpose.

Keywords: curriculum integration, everyday objects, higher education, HIV and AIDS, professional learning, readers' theatre

\section{INTRODUCTION}

This article presents a collective inquiry into creating a readers' theatre script as a vehicle for professional learning about workshopping HIV and AIDS curriculum integration research in higher education. Our primary focus is on our learning as a team of workshop facilitators. We concentrate on an introductory activity where workshop participants spoke about everyday objects in relation to their experiences and practices concerning HIV and AIDS in higher education. We explore how composing a readers' theatre script enabled us individually and jointly to initiate and enhance our own learning as university educators. 
We begin our article with a brief discussion of HIV and AIDS and curriculum integration in South African higher education, and then describe our professional backgrounds and mutual interest in HIV and AIDS education. We go on to outline the context of the workshop that gave rise to our exploration and then explain the introductory object activity. Thereafter we illustrate how we composed a readers' theatre script as an arts-based research practice. We then provide details about how we drew together our reflections on the readers' theatre script to create a series of thematic dialogue pieces and offer our collective interpretations of these pieces. To close, we consolidate our learning and consider implications.

\section{SETTING THE SCENE}

\section{HIV and AIDS: The struggle continues}

According to the United Nations (2011) it is important to celebrate the accomplishments made in terms of halting and reversing the spread of HIV and AIDS, but also not to forget that there are still new as well as pervasive, long-standing challenges. Millennium Development Goal 6 called for halting and reversing the spread of HIV and AIDS by 2015. In South Africa, however, it was estimated that in 2016 there were 7,1 million people living with HIV, 18,9 per cent adult HIV prevalence, 270000 new HIV infections, and 110000 AIDS-related deaths (AVERT 2016). It is clear that in South Africa there is still much work to be done in halting and reversing the spread of HIV and AIDS, and in attending to the social impact of the pandemic.

Four decades of HIV and AIDS challenges related to social as well as biomedical issues include "global inequality in access to treatment, persistent stigma, and the need for HIV prevention that women can use" (United Nations 2011, 1). To date no medical vaccine is available to prevent HIV; however, as educators and educational researchers we still believe that it is possible to do something about HIV and AIDS through teaching and learning in schools and in higher education.

Venables (2018) commends HIV and AIDS-related campaigns in South Africa, where stigma is confronted through education and where more open conversations about HIV are commonplace. One example is the manner in which the South African Department of Health conducts campaigns in civil society and through community organisations to actively encourage people to be tested and to seek antiretroviral treatment. Increased knowledge and awareness are making inroads into addressing issues related to HIV and AIDS in South Africa, but it is important that educators sustain and extend this work. Educators across all teaching institutions and contexts have opportunities to make a difference in teaching and learning contexts through the integration of HIV and AIDS education in curricula. 


\section{Curriculum integration of HIV and AIDS in higher education}

According to Drake and Burns (2004) there are three approaches to integration: multidisciplinary, interdisciplinary, and transdisciplinary. The main difference between the three approaches relates to the extent of separation between the subject areas that are integrated. There appears to be no agreement on the definition of curriculum integration, but Parker (2005, 425-453) describes the concept as:

“... a curriculum approach that purposefully draws together knowledge, perspectives, and methods of inquiry from more than one discipline to develop a more powerful understanding of a central idea, issue, person, or event. The purpose is not to eliminate the individual disciplines but to use them in combination."

Drake and Burns (2004) believe that regardless of the degree of integration which an educator may wish to adopt, they are usually able to adapt any one of the approaches to suit his or her own teaching context. Furthermore, educators may "use any of the approaches at any level of education, in a single classroom or in a team approach" (Drake and Burns 2004, 6).

The Policy and Strategic Framework on HIV and AIDS for Higher Education (Higher Education HIV and AIDS Programme [HEAIDS] 2012) advocates mainstreaming of HIV and AIDS throughout South African higher education institutions as well as HIV and AIDS education curriculum integration. In essence it mandates the need to evolve and implement curriculum integration using approaches that are context appropriate and innovative. We have taken up this challenge in presenting, sharing, and reflecting on our learning experiences as educational researchers who make public insights generated through our teaching, learning and workshopping in the area of HIV and AIDS curriculum integration.

\section{Locating ourselves and our mutual interest in HIV and AIDS education}

Our team comprises three female teacher educators from a research-intensive South African university. Linda is located in Mathematics Education, Kathleen in Teacher Development Studies, and Lungile in Gender and Curriculum Studies. Each of us has been involved with work in HIV and AIDS curriculum integration for more than a decade.

Linda has an interest in producing new knowledge through self-study research methods in the area of integration of HIV and AIDS education in curricula across higher education modules using a "starting with ourselves" approach. Her research in HIV and AIDS education makes use of arts-based methods such as making metaphor drawings, scrapbook pages, and storyboards. Linda's research in this area commenced by introducing HIV and AIDS education 
integration in the primary mathematics education modules that she taught (Van Laren 2011). Subsequently she has seen the need to engage in collaborate self-study with other researchers, at her own institution as well as at other South African higher education institutions, to reflect on and explore additional ways of encouraging and extending HIV and AIDS education and curriculum integration (Van Laren, De Lange and Tanga 2013).

Kathleen's scholarship focuses on professionals initiating and directing their own learning to enhance their continuing growth, and implications thereof for professional learning across multiple professions and academic disciplines. Her work has shown how reflexivity in professional learning can facilitate critical understandings of how lived experiences and beliefs interact with educational processes (Pithouse-Morgan et al. 2015). Kathleen's collaborative HIV and AIDS curriculum integration research with colleagues across higher education institutions has highlighted how arts-based and participatory modes can heighten engagement and deep thinking, dialogue and sharing, enjoyment, taking action, and emotional growth (Pithouse-Morgan et al. 2013).

Lungile's academic work focuses on gender and sexuality education. Her research interest in the area of HIV and AIDS stemmed from her work as a schoolteacher teaching Life Orientation, where issues of HIV and AIDS and sexuality education were encompassed. In her research she has looked at how sexuality and HIV and AIDS education could be integrated in other learning areas in a Grade 6 class (Masinga 2009). She also undertook a participatory study of teachers as sexuality educators in the context of HIV and AIDS in South Africa (Masinga 2012). Lungile's doctoral research revealed how the challenging of teacher positioning, when done in a supportive, interactive environment, can result in a repositioning of the self that brings teachers closer to becoming the teachers that they wish to be as they collectively influence change.

\section{The HIV and AIDS curriculum integration research workshop}

A colleague from a nearby university of technology, Delysia Timm, invited us to facilitate a one and a half day HIV and AIDS curriculum integration research workshop. At her university Delysia is the project leader of an HEAIDS-funded project where one of the aims is to promote and research the curriculum integration of HIV and AIDS. The 11 participants who attended the workshop were university educators and postgraduate students involved in the project, working across disciplines and departments at the university of technology.

In planning the workshop we decided to offer participatory activities to introduce creative ways of thinking and discussing topics and genres for research writing and research projects. Furthermore we wanted to introduce the participants to informal, free writing strategies, which 
we have found to be a helpful bridge to more formal academic writing and presentations (Elbow 2000). We designed a series of workshop activities that could be adapted by participants as creative analytical practices (Richardson 2004) for use in their own writing and research.

As the workshop facilitators we also elected to undertake collective arts-based self-study (Samaras et al. 2008) to share, explore, and extend our own professional learning. As Korthagen (2017, 392) highlights:

\footnotetext{
"Strong professionals can indeed be characterised by the fact that they regularly reflect on their experiences with the aim of improving their future behaviour. In other words, strong professionals learn from their experiences in a conscious and systematic manner through reflection."
}

We anticipated that a self-study research methodology would allow us to strengthen our practice through working together to unpack and learn from our experience of facilitating the workshop. Our mutual interest in using performative, visual, and literary arts-based methods as innovative modes of researching and facilitating professional learning informed our decision to try out readers' theatre (Donmoyer and Yennie-Donmoyer 1995) to connect and share with each other and potential audiences. Hence our research question was: What can we learn about workshopping HIV and AIDS curriculum integration research in higher education through collaboratively composing and reflecting on a readers' theatre script?

\section{USING EVERYDAY OBJECTS TO EXPLORE ENTANGLEMENTS OF HIV AND}

\section{AIDS}

For our self-study research we chose to concentrate on the workshop's introductory activity, where we examined everyday objects to explore the concept of "entanglements" (Mitchell 2017, 11) of HIV and AIDS in our lives as South Africans who teach and learn in higher education. According to Mitchell $(2017,12)$ there are intertwined and elaborate entanglements of objects with the lives of people, and the study of these complicated links to issues such as HIV and AIDS offers "a promising approach to deepening an understanding of everyday realities." Furthermore, Mitchell $(2017,14)$ notes that the use of inanimate things has been found to facilitate meaning making in a "grounded manner" in research across disciplines such as education, archaeology and communication.

The seminal work of Riggins (1994) emphasises that object study is possible in terms of both denotative (factual and technical) and connotative (personal and subjective) meanings. However, in addition to considering what the object is and what it is used for, and the meaning associated with the object, there are opportunities to use the object as a metaphor or symbol. 
Using an object metaphorically allows for creative, unique descriptions that are not necessarily literally applicable. Mitchell (2017) finds that personal connections made by exploring objects as metaphors assist with "contexualising ... so that we become more attuned to their significance" $(2017,22)$ in terms of, for example, integrating HIV and AIDS, and moreover allow for learning and "highlights the personal links to objects and things" (2017, 25).

To focus attention on the purpose of the workshop in an engaging, novel manner, we commenced by using objects in an icebreaker activity. We followed the object activity steps suggested by Mitchell (2017, 16-18):

Step 1. "Before the workshop Linda collected a variety of commonplace objects and placed them in an opaque bag. These included items such as a candle, rubber bracelet, plastic syringe, translucent plastic bag, pair of scissors, small container with jam, empty plastic container, and other random everyday objects that were on hand. There were no duplicates."

Step 2. "Lungile asked each of the seated participants to pull one of the unseen objects out of the opaque bag."

Step 3. "When each participant had drawn an object out of the bag, Lungile asked each person to hold up his or her selection and respond to this question: What does the object have to do with integrating HIV and AIDS? Lungile suggested that participants look at the object in terms of metaphorically relating to HIV and AIDS curriculum integration rather than considering the object in its 'literal sense'."

To stimulate responses Linda, who had pulled a candle from the bag, described how the candle could represent something that needed to be lit to make a difference. She explained how the process of lighting the candle makes a difference to one's surroundings, but the process requires finding the spark to light the candle to encourage HIV and AIDS curriculum integration. As illustrated in the readers' theatre script below, Lungile then invited workshop participants to follow suit in offering their individual responses. Kathleen and Lungile also took part by offering responses to objects they had pulled from the bag: a pink plastic bangle (Kathleen) and a syringe (Lungile).

\section{CREATING A READERS' THEATRE SCRIPT}

As a creative analytical research practice, readers' theatre is a process where researchers produce a dramatic script from edited extracts of a research transcript (Donmoyer and YennieDonmoyer 1995). Readers' theatre aims to capture authentic dimensions of human experience using creative performance arts (Pelias 2008) in working with research data (Donmoyer and Yennie-Donmoyer 1995). The goal is to produce a script comprising narration and dialogue that permits a give-and-take and participatory involvement by performers and the audience as an "inclusive way of knowing" (McMillan and Price 2005, 143). The script is then rehearsed 
by a group and read aloud for an audience rather than learned by heart. As Flynn $(2004,360)$ explains, this is because "the emphasis is on spoken words and gestures, not on staged action or blocking (the official theater term for stage movement)".

We began our readers' theatre process by sitting together to watch a video of the workshop that had been recorded by a student assistant at the university of technology. We focused on the object icebreaker activity and watched this part of the video repeatedly to see what we could use as a basis for our script. After sharing and reflecting on our individual responses to what each workshop participant had said about her or his object, and considering connections across what various participants had said, we agreed to choose three participants as the main characters for the script: Crispin Hemson, Nareen Gonsalves, and Delysia Timm.

We then transcribed what Crispin, Nareen, and Delysia had said about their objects. Next, we met together again to read, edit, and rearrange extracts from the transcript to create a succinct script. In editing and rearranging text we paid attention to enhancing the flow, coherence, and impact of the script, which we titled Containing HIV and AIDS. We added a narrator's voice to describe the action.

At this point, to seek consent from Crispin, Nareen and Delysia, via e-mail communication we sent each the following email:

"We are writing a self-reflexive piece drawing on the HIV and AIDS Integration workshop that we facilitated. We are focusing particularly on our co-learning from facilitating the object activity that we did to start off the workshop. As an exemplar, we would like to include a short transcription from the video where you are discussing your object and also a screenshot from the video showing you holding your object (please see attached). We would like to ask your permission to include this transcription, the screenshot and your name in our article. Please could you let us know if you would be happy with that."

All three participants sent e-mail communications giving us consent to use their names, words and screenshot video images. Our intention in making public their images and names was to acknowledge their vital contributions to our learning.

\section{THE SCRIPT: CONTAINING HIV AND AIDS}

Narrator: "Lungile turns to Crispin."

Lungile: “Crispin, what's your object?"

Narrator: "Crispin holds up an empty, translucent plastic bag."

Crispin: "What struck me was that when I put the bag down here on the desk, it sort of heaved up and down."

Narrator: "Crispin gently shakes the bag open and lays it out on the desk." 
Narrator: "Crispin pauses to watch the bag. He then gestures with both hands to the bag, which has started moving slightly up and down in the current of the air-conditioning."

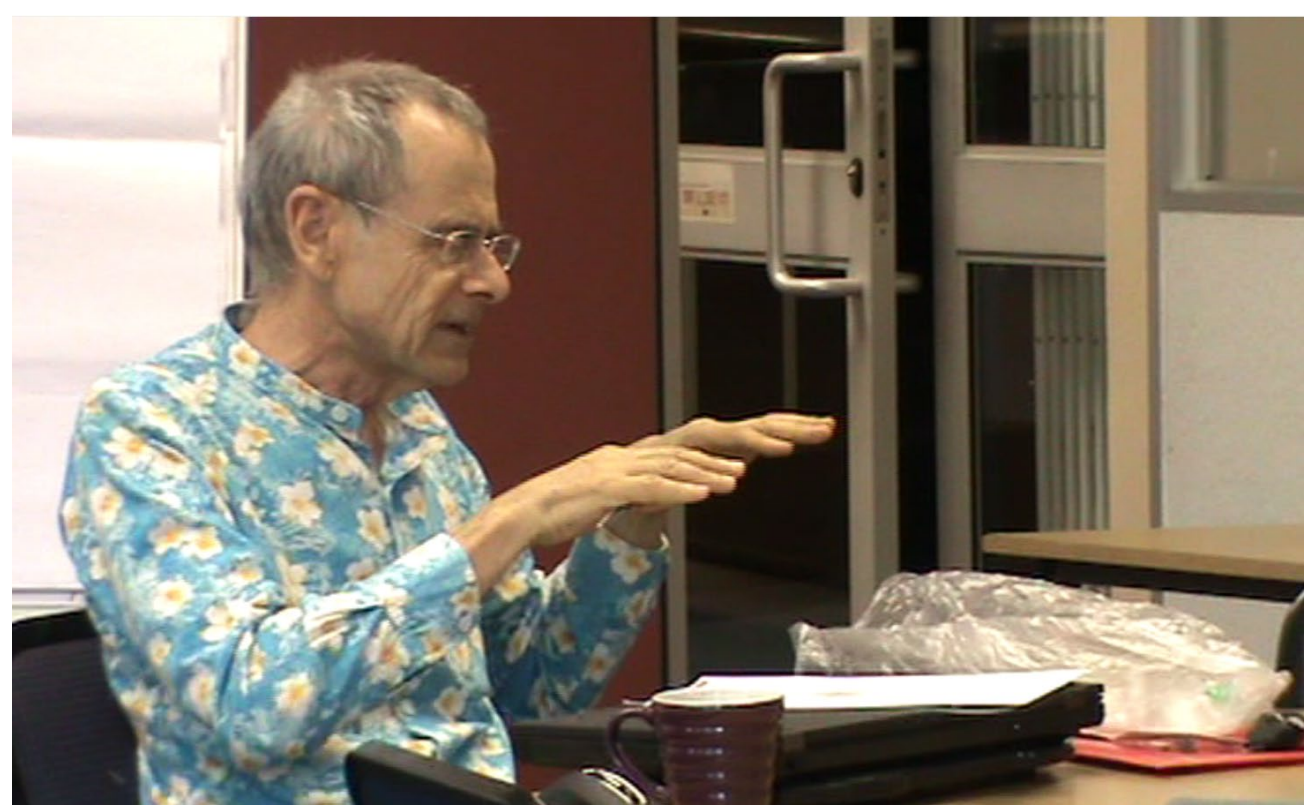

Figure 2: Crispin mimicking the movement of the plastic bag

Crispin: "But, you know, I am thinking about breath, people's breath. And, being in a group of students talking about the impact of HIV in families in particular, because although we didn't ask them to talk about their families, that's actually what they spoke about."

Narrator: "Crispin pauses and watches the bag moving softly."

Crispin: “And, I think, everyone must have been, everyone's breath must have been caught in this. You know, the things that interfere with breathing, anxiety, fear-whatever makes people breathe out of rhythm."

Narrator: "Lungile nods to Nareen."

Lungile: "OK, Nareen."

Narrator: "Nareen holds up a small, empty, transparent container."

Nareen: "I have a container, an empty one. But really, when you think about it, it has so much potential to hold so many different things. If I look at this in relation to our HIV integration, when I started off, literally my whole experience and everything I knew about it was contained in this little container, because you sort of put it in and leave it somewhere. And that's basically what happened. But suddenly when we were in the project, you started reflecting on all your experiences. And so, the container had to be opened."

Narrator: Nareen opens the container.

Nareen: "And a lot of stuff came forward. Not just for me, but for everybody else as well. All the discussions, all the learnings that happened. And I find the same thing happening in the classroom. We go in with this little topic. Or, we think, a little topic. And you open it in the class and it's literally like opening a can of worms because you're not always prepared for what hits you when you open that container." 


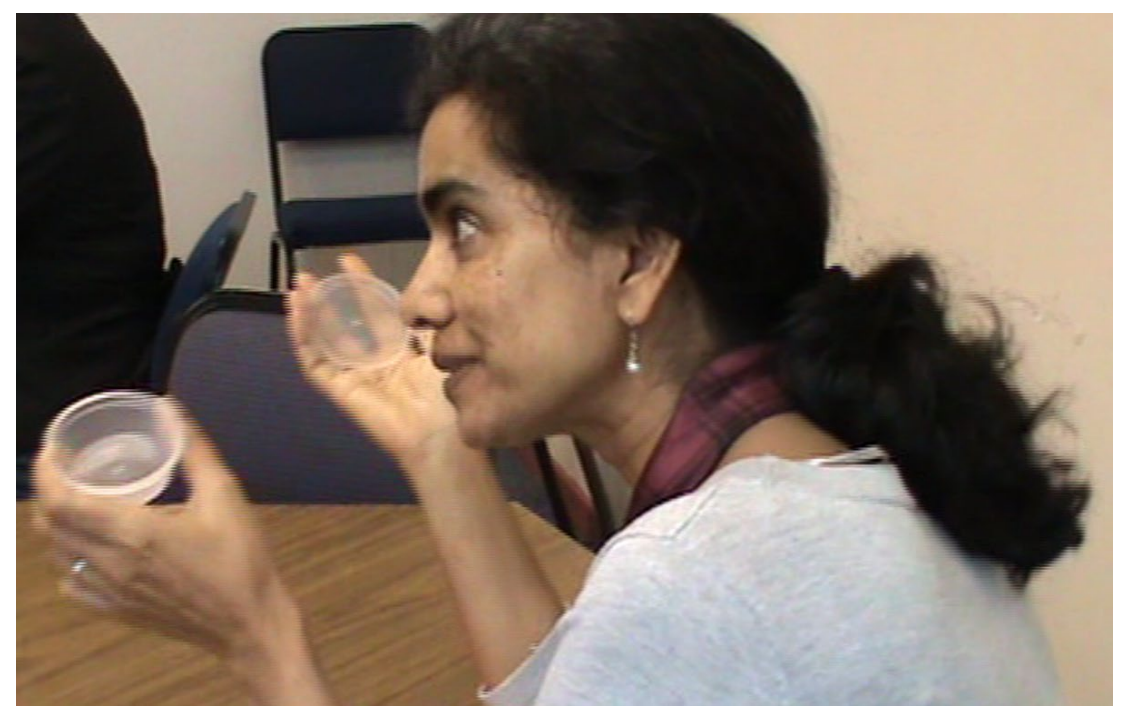

Figure 3: Nareen opening the empty container

Nareen: "Actually, quite often it's overflowing and we just put a lid on it. And you open the lid and it's a bit of an explosion sometimes."

Narrator: Lungile signals to Delysia.

Lungile: "Yes, Delysia."

Narrator: Delysia holds up a small plastic jam container.

Delysia: "For me, one thing I thought of is packaging. You can package a whole big pot of jam in small amounts and make it accessible to many people, any time, wherever they are. For me, working in this project, I've realised that things in small amounts, packaged neatly, people can take and use anywhere and wherever they go. It's not limited and is actually extending the shelf life and the usability of that. And it's making sure that it's effective but also that it's accessible and transferable to all kinds of situations."

Narrator: "Delysia pauses and turns the container over in her hand."

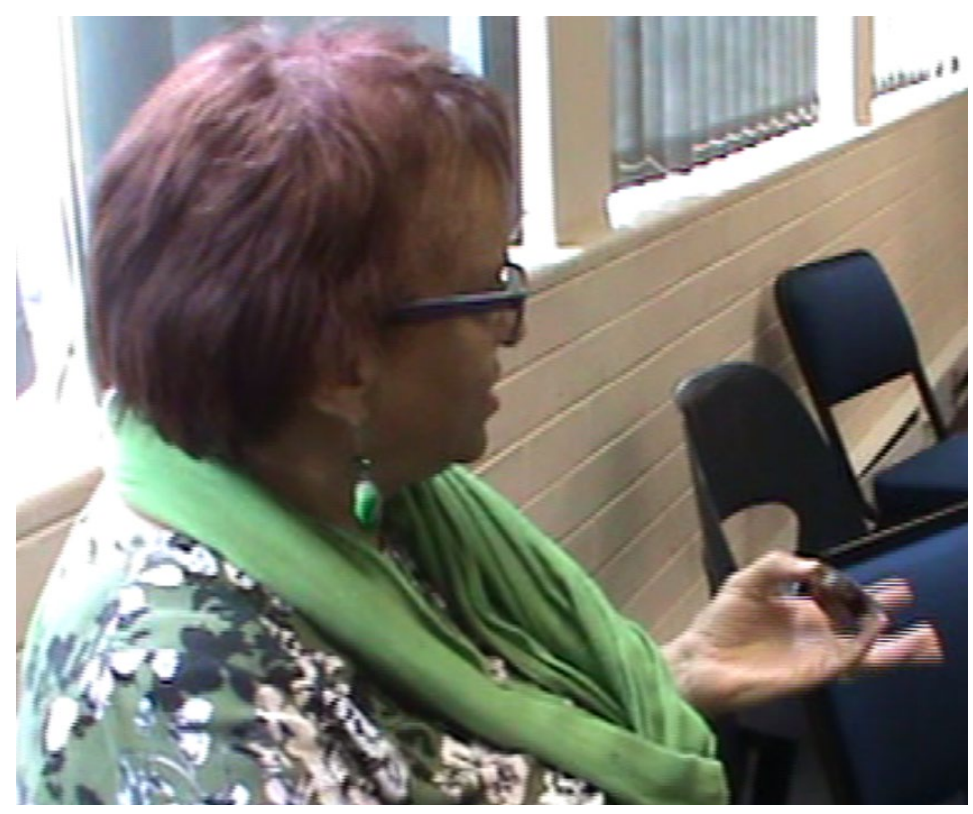

Figure 4: Delysia turning over the jam container 
Delysia: Also, for myself it makes me ask 'How do you eat an elephant? A small bite at a time'. So you don't have to be involved with the whole messy big pot of stuff. You can just have a small bite."

\section{USING DIALOGUE TO UNPACK OUR PROFESSIONAL LEARNING}

In this section we return to our guiding question: What can we learn about workshopping HIV and AIDS curriculum integration research in higher education through collaboratively composing and reflecting on a readers' theatre script? A sequence of three thematic dialogue pieces communicates our individual and collective learning in an interactive way. As a literary arts-based device, dialogue can offer readers insight into the various characters in a story and show how growth happens through contact between characters (Coulter and Smith 2009). Furthermore, as a mode of thinking for qualitative data analysis dialogue "provides the ... generative space to unpack, reflect upon, criticize, and reconsider the variety of opinions offered on an issue", thus producing significant learning and understanding (Freeman 2017, 58). Our use of dialogue builds on the work of self-study researchers who have explored dialogue as a creative analytical practice to reconsider their professional learning through self-study (e.g. East, Fitzgerald and Heston 2009). In previous research we have found that thematic dialogue pieces can facilitate "introspection and self-critique" as self-study researchers and "serve as portals through which readers can enter into the particularity and complexity of our experiences" (Pithouse-Morgan et al. 2015, 166).

The dialogue pieces that follow are composed of lightly edited excerpts from transcripts of an audio-recorded reflection on our experiences of creating the readers' theatre script. We first transcribed our conversation and then later read the transcript together to identify emerging themes in relation to our research question. Coloured highlighters were used to connect similar ideas. Then we clustered these ideas together and slowly modified the transcript to create a series of short dialogue pieces, each of which focused on one key aspect of our learning. The three final pieces were composed through an iterative, collective process of revising and further revising. In what follows each dialogue piece is complemented by a shared interpretation of our learning as portrayed in the piece.

\section{Dialogue Piece 1: "Objects as containers and connectors"}

Linda: The object activity didn't take much. It was inexpensive and the participants could link to what they were doing with just these random objects.

Kathleen: And it's simple, cheap, and portable. 
Lungile: It's also easy to explain. And the objects themselves help participants to feel "OK, this is not going to be a complicated thing".

Kathleen: I think that because the object is something that you can hold and touch, it gives a sense of security. You feel, "OK, I can say something about this thing because it's right here".

Linda: And the object is a common thing rather than an obscure thing that you have never seen in your life before. These were just any old objects, yet everybody could say something that was ....

Kathleen: ... quite profound ....

Linda. Yes! And they didn't get much time to think about it. It was improvised and yet they were able to communicate their ideas quite effectively, just by talking about the objects. Also, the objects became metaphors for their practice.

Lungile: And because of the metaphors, participants could control what they shared, what they wanted to share, and how they would share it.

Kathleen: I suppose that's also what the object activity shows each person, their own learning, in a new way - and each other's obviously, because it's not an individual activity.

Linda: Also, the object activity is not just an icebreaker.

Lungile: This activity is a starting point for the larger conversation - it's linked to the whole process, not an isolated thing.

Kathleen: It's a connector.

Lungile: The participants came from different contexts and I saw how their learning was advanced just by listening to people from other disciplines and departments. Listening to others in different fields talk about their practice opens up possibilities. We can see that HIV and AIDS isn't meant for specific disciplines or departments only; in any higher education space we can actually integrate and speak of it.

Kathleen: That is the value of the creative and participatory activities that serve this containing function in a group. It's a way of bringing people together and making everyone feel that they've got something to contribute. It gives everyone a space and a time to speak and be heard, right from the beginning. What so often happens in workshops is that we have a few people speak up and everyone else sits quietly. But when you have started the workshop with this object activity, everybody has spoken. So, even if they don't speak again, they have still contributed and you have ....

Linda: $\quad$... acknowledged them.

\section{Our interpretation}

We commenced the icebreaker activity by bringing out the unseen objects in a closed, opaque container. This bag may be construed as the "black box" of discussion we wanted to generate with the participants. The random distribution of the objects symbolises how we as workshop facilitators relinquished some of our control over the discussion by inviting the participants to remove the objects from our opaque, black box container. The participants were thus offered the opportunity to take some control over what was presented and shared at the outset of the workshop.

The participants' responses on objects were not presented in terms of the objects' physical 
properties, but rather as "material points of departures and material vessels for creative engagement" (Meskin et al. 2017, 175) to reflect on the participants' professional practices and experiences. In other words, the participants used the objects metaphorically to signal the entanglement (Mitchell 2017) of HIV and AIDS in their everyday professional lives. Although the object activity did not require complicated, time-consuming preparation and none of the items had to be purchased for the activity, this economical way of encouraging active participation and reflection allowed each person to see and share his or her entanglements in a unique manner using his or her own terms of reference (Mitchell 2017).

Significantly, the objects became points of connection between participants and across diverse disciplines and departments. As Samaras et al. (2016, 163) highlight:

"Whereas university educators historically work in an individualistic and segregated fashion reflecting the 'different vocabularies' of diverse disciplines ... a conversation across specialisations ... [can] offer an opportunity to generate a new, shared language that [can] be negotiated and reviewed through dialogue."

Making transdisciplinary connections in higher education has implications for enhancing both research and teaching by bringing into dialogue multiple ways of knowing and learning (Gast, Schildkamp and Van der Veen 2017). With respect to HIV and AIDS curriculum integration in the South African higher education context, collaboration and sharing across long-established academic and professional boundaries can help to counteract a "sense of working at a distance from colleagues ... and a lack of collegial support" commonly experienced by university educators "in their efforts to integrate HIV \& AIDS" (Van Laren et al. 2012, 152).

\section{Dialogue Piece 2: "The containing space"}

Lungile: "The workshop itself became a kind of container because it offered a safe space for expression. As facilitators and participants we contained the environment and the knowledge that we shared. And the emotions that were part of that process."

Kathleen: "The container metaphor is so important because the object activity can happen in any space, but it has to be a contained space. The activity provides a contained space that is very free in some ways, but where people feel safe. Having a simple activity with certain steps to follow alleviates anxiety because, as a participant, you don't have to think too much about what to do."

Linda: "Also, it's important that we told people that they could say 'I don't know now, but come back to me'. In other workshop situations people might not get a chance to say 'I do have a point, but I'm still processing how I will say it'. Because of how we created that space, they were allowed that opportunity."

Lungile: "It was a very flexible environment." 
Kathleen: "Sometimes people are so frightened of making mistakes that they won't contribute. Here we were saying 'There are no mistakes to be made'."

Linda: "There's no right or wrong."

Lungile: "There was also a sense of curiosity about the method itself."

Kathleen: "That speaks to the importance of metaphorical and creative participatory activities within this contained space, as part of the containing process. If we just sat down and said 'OK, everybody, we want you to talk about your experiences of integrating HIV and AIDS', I don't think we'd get the same depth. People were talking about things that were highly emotional, and yet I certainly didn't pick up any feelings of anxiety in the group. And usually, as a facilitator, you do pick that up."

Linda: "And the readers' theatre script is signalling the idea of entanglement, of how HIV and AIDS is actually entangled in our lives in many different ways."

Kathleen: "HIV and AIDS is so difficult to get hold of, such an emotionally overwhelming, and proliferating thing. But if we can provide these small, containing spaces it is a way to, as Delysia said, eat the elephant one bit at a time."

Linda: "I think that if you do offer it in a small piece, then maybe you can facilitate hope more significantly. Hope makes you want to try. Because it is about trying, to get things moving. With people still getting infected, we could just say 'What's the point?' That's a loss of hope."

Kathleen: "At least if we can begin to address that loss of hope, that is an accomplishment. But if we only measure our work in terms of HIV infection rates, then ...."

Linda: " “... then we can become very depressed."

Lungile: "So we want to say 'There is hope. There are always new ways of teaching and speaking about HIV and AIDS. And this is one of those ways'."

\section{Our interpretation}

Our learning came from understanding the importance of contained spaces for beneficial participation in workshops using creative methods, especially workshops dealing with potentially sensitive issues, such as HIV and AIDS. By contained spaces we mean spaces that permit emotions to be experienced and shared in an emotionally safe way (Dale and James 2015). Through a creative and metaphoric method such as the object activity we were able to provide what turned into a protective containment for the process. Upon reflection as facilitators we recognised the role of the object activity in what we were able to achieve, based on its nature and simplicity. The activity was easy to understand and perform, and gave opportunity for free expression with lack of pressure for participants. We were also reminded that in discussing issues of HIV and AIDS there is always the potential for participants to experience anxiety. However, due to the contained space that was created, we as facilitators did not observe any constraining anxiety. In our view this contained space allowed participants to ponder and converse about anxiety-provoking feelings with people who could lend an ear (Elfer and Dearnley 2007). 
At the centre of our learning is the entanglement of HIV and AIDS. We acknowledged HIV and AIDS as a difficult entity to come to terms with, as it is intimidating, emotionally difficult, and often overwhelming. As a source for discussion, HIV and AIDS can yield silence and withdrawal from participants. It also has the potential to evoke unforeseen emotions, leading to further withdrawal from active participation, thus affecting the success of the workshop. By using a creative method in a contained space we were also containing the discussion about HIV and AIDS in a way that provided a sense of sharing, safety and hopefulness.

\section{Dialogue Piece 3: "Containing our learning"}

Kathleen: "It was interesting that all three objects, the plastic bag, the jam pot, and the other little empty container, were containers of a kind. It wasn't that all the objects we gave out were containers, but it's interesting that those were the ones that we picked out for the script. It wasn't that we were thinking about them as containers at the time, but we picked them out spontaneously and intuitively because of what had been said about them by Crispin, Delysia, and Nareen."

Linda: "They each spoke of contained entanglements."

Kathleen: "I think that what emerged was our shared intuitive feeling about the importance of containment, but not, as Nareen pointed out, the unhealthy kind of containment where you push things down and out of the way."

Linda: "Where it's locked in and it just stays like that, inert."

Kathleen: "And in terms of creating the script, I suppose that's another way of containing. We had to choose limited examples and put them in a concise script."

Lungile: "But the examples also had to speak to each other for the script to have a sense of flow and coherence."

Linda: "They connected."

Lungile: "Yes, although the objects themselves were not originally chosen with that aim."

Kathleen: "Only when we looked at the script as a whole did we see the thread of 'container' running through it. Creating the script itself, as a form of analysis, helped us to see the ways in which we were making sense of what happened."

Linda: "So the script is not just containing the HIV and AIDS, it's containing our learning."

Kathleen: "Yes, and showing it to us. And the script writing might have been completely different if each of us had individually chosen examples rather than making collective choices."

Linda: "If we presented this at a conference it would be interesting to get other people to interpret the script."

Kathleen: "Yes! Rather than giving them our interpretations, we could then elicit another layer of meaning. We could perform the script and then ask people what they notice. They might not see the container metaphor running through it as we do, but they would offer us some new learning." 


\section{Our interpretation}

We frequently make use of arts-based methods in research projects, and we are always keen to explore alternative strategies for reflection and professional experience presentation. Kathleen suggested that we collaboratively prepare a readers' theatre script as a vehicle to explore our object activity; she had attended an interesting conference presentation where she was introduced to readers' theatre as a form of creative analytical practice in qualitative inquiry. Because the object activity had been video recorded, we could later view the 11 participants' object reflections to find material for our script. Each participant explained the entanglement of HIV and AIDS and the object using unique, thought-provoking metaphors. We limited our object descriptions to three because we wanted to provide the detailed discussion offered by particular participants. Through consensual choice we then selected the descriptions of Crispin, Nareen and Delysia as representative of the workshop participants' responses. Only after we had selected these three object descriptions to create the readers' theatre script did we note that all of the objects were containers - a plastic bag, an empty container, and a container filled with jam. In this way the script became a mirror in which we could see our own learning about the value of arts-based, participatory activities for containing and connecting professional learning in higher education, particularly in relation to emotionally sensitive areas such as HIV and AIDS.

On reflection, we see that the containers picked up by Crispen (the plastic bag), Nareen (the empty container) and Delysia (the small jam container) also have metaphoric significance for strengthening our professional learning as educators and researchers in higher education. First, the flimsy plastic bag symbolises the fragility of learning, teaching, and researching about HIV and AIDS in South Africa, where many people experience HIV and AIDS-related emotional and social challenges. This open plastic bag also reminds us that we cannot presume that the emotional strain experienced by millions of South Africans can be ignored by those who might feel that they are not directly affected by this widespread pandemic - we are all part of the air that flows in and out of the open bag. Being part of this air, we in higher education are responsible for producing generative ways of knowing and doing in relation to HIV and AIDS. Through higher education research that offers pragmatic suggestions for academics and researchers, it is possible to have far-reaching influence. Second, the closed, more substantial plastic container held by Nareen offers a hint to be mindful of how some educators might shy away from the emotional complexities of HIV and AIDS for fear of what might happen if this "can of worms" was opened in the classroom. Finally, the small jam container filled with something sweet symbolises the positive, more hopeful learning opportunities offered in opening up to HIV and AIDS. This may be facilitated when the topic is explored in a sensitive, 
considerate manner through participatory and creative activities in a contained environment where vulnerabilities are acknowledged and respected.

\section{CONSOLIDATING OUR LEARNING}

The Policy and Strategic Framework on HIV and AIDS for Higher Education (HEAIDS, 2012) mandates the development and practice of HIV and AIDS education curriculum integration using approaches that are context appropriate and inventive. We have responded to this mandate by making public our insights generated through workshopping in the area of HIV and AIDS curriculum integration in higher education.

Using everyday objects to open up conversations enabled sharing of HIV and AIDS teaching and learning experiences and practices. Each participant was given the opportunity to share a response evoked by an object picked at random. In addition, each participant could convey this message within self-determined boundaries, thus offering them some agency. The objects also served as points of connection between participants and across diverse disciplines and departments, thus bringing into dialogue multiple professional perspectives and practices. Hence the deceptively simple, yet versatile object activity provided an insightful entanglement of responses evoked by unremarkable objects in relation to HIV and AIDS.

In composing the readers' theatre script we selected the object responses offered by Crispin, Nareen and Delysia to illustrate the outcomes of our object activity. In dialoguing about the script we became conscious that each of these responses was prompted by some kind of container. We further came to see how, through a creative and metaphoric method such as the object activity, we were able to provide what turned into a protective containment for exchanges about integrating HIV and AIDS. As a vital part of our learning, we came to a realisation of the value of creative and hopeful ways to have an old and sometimes depressing conversation. Reflecting on the object activity reminded us that it is necessary for us to sustain conversations about HIV and AIDS as part of our lived experience in higher education in South Africa.

Through our collaborative arts-based inquiry, we recognised that composing the readers' theatre script provided generative and thought-provoking possibilities for interrogating and strengthening our professional learning as educators and researchers in higher education. The script became a mirror in which we could see our own learning about the value of arts-based, participatory activities for containing and connecting professional learning in higher education, particularly with respect to emotionally laden areas such as HIV and AIDS. Our learning also came from understanding how methodologically inventive ways of knowing (Dadds and Hart 2001) such as reader's theatre can assist in further reinventing the means of how we continue to dialogue and do research around issues of HIV and AIDS. We offer our self-study research 
process and the ensuing professional learning as an invitation to others in higher education who are interested in facilitating and participating in complex conversations, especially in relation to sensitive and challenging areas such as HIV and AIDS curriculum integration.

\section{ACKNOWLEDGEMENTS}

We are thankful for the contributions of all participants in the December 2016 workshop, and we especially thank Crispin Hemson, Nareen Gonsalves, and Delysia Timm for kind permission to include their names, words, and images in this article.

Ethical clearance was obtained from our institution to study university educators' lived experiences of HIV and AIDS curriculum integration in higher education. In line with the undertakings that we made in order to obtain ethical clearance, the data represented in this article are used with the explicit consent of all involved.

We gratefully acknowledge support and grant funding from the National Research Foundation of South Africa (Grant Numbers 90380 and 91070 and Incentive Funding for Rated Researchers). We further acknowledge that any opinions, findings, conclusions, or recommendations expressed in this material are those of the authors, and therefore the funders do not accept any liability in regard thereto.

\section{REFERENCES}

AVERT. 2016. HIV and AIDS in South Africa. https://www.avert.org/professionals/hiv-aroundworld/sub-saharan-africa/south-africa (Accessed 5 January 2018).

Coulter, Cathy A. and Mary Lee Smith. 2009. The construction zone: Literary elements in narrative research. Educational Researcher 38(8): 577-590.

Dadds, Marion and Susan Hart. 2001. Doing practitioner research differently. London, UK: RoutledgeFalmer.

Dale, Di and Chris James. 2015. The importance of affective containment during unwelcome educational change: The curious incident of the deer hut fire. Educational Management Administration \& Leadership 43(1): 92-106.

Donmoyer, Robert and June Yennie-Donmoyer. 1995. Data as drama: Reflections on the use of readers' theater as a mode of qualitative data display. Qualitative Enquiry 1(4): 402-428.

Drake, Susan M. and Rebecca Crawford Burns. 2004. Meeting standards through integrated curriculum. Alexandria, VA: Association for Supervision and Curriculum Development.

East, Katheryn, Linda, M. Fitzgerald and Melissa L. Heston. 2009. Talking teaching and learning: Using dialogue in self-study. In Research methods for the self-study of practice, ed. Deborah Tidwell, Melissa L. Heston and Linda M. Fitzgerald, 55-72. New York: Springer.

Elbow, Peter. 2000. Everyone can write: Essays toward a hopeful theory of writing and teaching writing. New York: Oxford University Press.

Elfer, Peter and Katy Dearnley. 2007. Nurseries and emotional well-being: Evaluating an emotionally containing model of professional development. Early Years 27(3): 267-279.

Flynn, Rosalind M. 2004. Curriculum-based reader's theatre: Setting the stage for reading and retention. The Reading Teacher 58(4): 360-365. 
Freeman, Melissa. 2017. Modes of thinking for qualitative data analysis. New York: Routledge.

Gast, Inken, Kim Schildkamp and Jan T. van der Veen. 2017. Team-based professional development interventions in higher education: A systematic review. Review of Educational Research 87(4): 736-767.

Higher Education HIV and AIDS Programme. 2012. Policy and strategic framework on HIV and AIDS for higher education. Pretoria: Higher Education HIV/AIDS Programme. https://heaids.org.za/ site/assets/files/1246/policy_and_strategic_framework_on_hiv_and_aids_for_higher_ education.pdf (Accessed 3 February 2018).

Korthagen, Fred. 2017. Inconvenient truths about teacher learning: Towards professional development 3.0. Teachers and Teaching 23(4): 387-405.

Masinga, Lungile. 2009. An African teacher's journey to self-knowledge through teaching sexuality education. In Making connections: Self-study \& social action, ed. Kathleen Pithouse, Claudia Mitchell and Relebohile Moletsane, 237-252. New York: Peter Lang.

Masinga, Lungile. 2012. Journeys to self-knowledge: Methodological reflections on using memorywork in a participatory study of teachers as sexuality educators. Journal of Education 54: 121 137.

Meskin, Tamar, Tanya van der Walt, Lee Scott, Chris de Beer and Kathleen Pithouse-Morgan. 2017. Shoes, suitcases, stones: Creative engagement with ourselves as artist-researcher-teachers through object inquiry. In Object medleys: Interpretive possibilities for educational research, ed. Daisy Pillay, Kathleen Pithouse-Morgan and Inbanathan Naicker, 175-196. Rotterdam, Netherlands: Sense.

McMillan, Sally and Margaret A. Price. 2005. A representative journey of teachers' perceptions of self: A readers' theater. In Advances in research on teaching, 11: Learning from research on teachers: Perspective, methodology, and representation, ed. Jere E. Brophy and Stefinee E. Pinnegar, 137169. Amsterdam, Netherlands: Elsevier Publishers.

Mitchell, Claudia. 2017. "Object as subject: Productive entanglements with everyday objects in educational research. In Object medleys: Interpretive possibilities for educational research, ed. Daisy Pillay, Kathleen Pithouse-Morgan and Inbanathan Naicker, 11-28. Rotterdam, Netherlands: Sense.

Parker, Walter C. 2005. Social studies in elementary education. 12th Edition. Columbus, OH: Pearson Merrill, Prentice-Hall.

Pelias, Ronald J. 2008. Performative inquiry: Embodiment and its challenges. In Handbook of the arts in qualitative research, ed. J. Garry Knowles and Andra L. Cole, 185-193. Thousand Oaks, CA: Sage.

Pithouse-Morgan, Kathleen, Naydene de Lange, Claudia Mitchell, Relebohile Moletsane, Tilla Olivier, Jean Stuart, Linda van Laren and Lesley Wood. 2013. Creative and participatory strategies for teacher development in the age of AIDS. In More and better teachers for quality education for all: Identity and motivation, systems and support, ed. Jackie Kirk, Martial Dembélé and Sandra Baxter, 75-90. Montreal, Canada: Collaborative Works.

Pithouse-Morgan, Kathleen, Nithi Muthukrishna, Daisy Pillay, Linda van Laren, Therisa Chisanga, Thenjiwe Meyiwa, Relebohile Moletsane, Inbanathan Naicker, Lorraine Singh and Jean Stuart. 2015. Learning about co-flexivity in a transdisciplinary self-study research supervision community. In Polyvocal professional learning through self-study research, ed. Kathleen Pithouse-Morgan and Anastasia P. Samaras, 145-171. Rotterdam, Netherlands: Sense.

Richardson, Laurel. 2004. Creative Analytical Practice (CAP) Ethnography. In Encyclopedia of Social Science Research Methods, Vol. 1, ed. Michael Lewis-Bec, Alan E. Bryman and T. Futing Liao, 212-213. Thousand Oaks, CA: Sage.

Riggins, Stephen H. 1994. Fieldwork in the living room: An autoethnographic essay. In The socialness of things: Essays on the socio-semiotics of objects, ed. Stephen H. Riggins, 101-147. Berlin, Germany: Moutin de Gruyter. 
Samaras, Anastasia P., Mary Adams-Legge, Deanna Breslin, Kavita Mittapalli, Jennifer Magaha O'Looney and Dawn Renee Wilcox. 2008. Collective creativity: A learning community of selfstudy scholars. In Learning communities in practice, ed. Anastasia P. Samaras, Anne R. Freese, Clare Kosnik and Clive Beck, 133-147. Dordrecht, Netherlands: Springer.

Samaras, Anastasia, Kathleen Pithouse-Morgan, Theresa Chisanga, Joan Lucy Conolly, Lynne Scott Constantine, Thenjiwe Meyiwa, Lesley Smith and Delysia Timm. 2016. Networkism: Transcontinental dialoguing about co-facilitating transdisciplinary self-study professional learning communities. In Enacting self-study as methodology for professional inquiry, ed. Dawn Garbett and Alan Ovens, 163-170. Herstmonceux, UK: Self-Study of Teacher Education Practices (S-STEP).

United Nations. 2011. Introduction. United Nations Chronicle 48(1). https://unchronicle.un.org/ issue/hivaids-fourth-decade (Accessed 10 September 2017).

Van Laren, Linda. 2011. Integrating HIV\&AIDS education in pre-service Mathematics Education for social justice. South African Journal of Education 31: 333-344.

Van Laren, Linda, Naydene de Lange and Pius Tanga. 2013. Breaking out of the cocoon: academics' experiences of integrating HIV and Aids into the curriculum. Acta Academica 45(3): 291-317.

Van Laren, Linda, Claudia Mitchell, Ronicka Mudaly, Kathleen Pithouse-Morgan and Shakila Singh. 2012. Exploring university educators' lived experiences of curriculum innovating through integrating HIV \& AIDS. Alternation 19(2): 138-161.

Venables, Emilie. 2018. HIV is still taboo in the DRC: Chronicles from Kinshasa. The Conversation. August 29, 2017. https://theconversation.com/hiv-is-still-taboo-in-the-drc-chronicles-fromkinshasa-82931 (Accessed 4 February 2018). 